\title{
ORIGINAL ARTICLE Heritable differences in fitness-related traits among populations of the mustard hill coral, Porites astreoides
}

\author{
CD Kenkel ${ }^{1,2}$, SP Setta ${ }^{1}$ and MV Matz ${ }^{1}$
}

A population's potential for rapid evolutionary adaptation can be estimated from the amount of genetic variation in fitnessrelated traits. Inshore populations of the mustard hill coral (Porites astreoides) have been shown to be more tolerant to thermal stress than offshore populations, but it is unclear whether this difference is due to long-term physiological acclimatization or genetic adaptation. Here, we evaluated variation in growth rate and survival among 38 families of juvenile recruits of $P$. astreoides spawned by colonies originating from inshore and offshore locations. Recruits were reared in a common garden for 5 weeks and then subjected to two thermal treatments $\left(28\right.$ and $\left.31^{\circ} \mathrm{C}\right)$ for 2.5 weeks. The most significant effects were detected during the first 5 weeks, before thermal stress was applied: $27-30 \%$ of variance in growth and $94 \%$ of variance in recruit survival was attributable to parental effects. Genotyping of eight microsatellite loci indicated that the high early mortality of some of the recruit families was not due to higher inbreeding. Post treatment, parental effects diminished such that only $10-15 \%$ of variance in growth rate was explained, which most likely reflects the dissipation of maternal effects. However, offshore-origin recruits still grew significantly less under elevated temperature compared with inshore-origin recruits. These differences observed in naive juvenile corals suggest that population-level variation in fitness in response to different thermal environments has a genetic basis and could represent raw material for natural selection in times of climate change.

Heredity (2015) 115, 509-516; doi:10.1038/hdy.2015.52; published online 17 June 2015

\section{INTRODUCTION}

Determining the amount of genetic variability in traits under selection is essential for evaluating a population's potential for evolutionary change (Charmantier and Garant, 2005). The heritability of a trait is the proportion of phenotypic variation due to genetic variation between individuals $\left(H^{2}=V_{\mathrm{G}} / V_{\mathrm{P}}\right)$ and largely determines the magnitude and speed of phenotypic change in response to selection (Falconer and Mackay, 1996). Predicting response to selection is particularly important for reef-building corals, which experience substantial environmental variation across species ranges (Hughes et al., 2003) and are undergoing climate change at an unprecedented rate (Burrows et al., 2011).

Corals are cnidarians that exist in symbiosis with dinoflagellates of the genus Symbiodinium. This symbiosis is considered obligate for the host as it has been estimated that up to $95 \%$ of a coral's energy requirements are met through photosynthetically fixed carbon contributed by the endosymbiont (Muscatine, 1990). Thermal stress results in the functional loss of the endosymbionts in the process known as coral bleaching, which can ultimately result in death if stressful conditions persist (Brown, 1997). Although reef-building corals are found throughout warm tropical and subtropical waters, many exist within $1-2^{\circ} \mathrm{C}$ of their temperature tolerance limit during summer months (Jokiel, 2004). Climate change models predict that global ocean temperatures will increase by $1-2{ }^{\circ} \mathrm{C}$ within the next 50 to 100 years (Hoegh-Guldberg et al, 2007), therefore putting thermally sensitive corals in jeopardy.
Thermotolerance limits of the coral holobiont (the collective unit of the coral host and all its symbionts) are greatly influenced by the type of Symbiodinium hosted. Substantial variation exists in thermotolerance among genotypes of Symbiodinium (Robinson and Warner, 2006; Howells et al., 2011) that affects holobiont growth (Little et al., 2004; Jones and Berkelmans, 2010) and bleaching thresholds (Oliver and Palumbi, 2011). In addition, high broad-sense heritability estimates for functional traits in Symbiodinium suggests that thermal adaptation of symbionts will have an important role in coral response to climate change (Csaszar et al, 2010), although it must be noted that this heritability was measured in hospite and some of it could have been attributable to the host. Coral thermotolerance limits are affected by host genetic background (Ulstrup et al., 2006; Abrego et al., 2008; Baird et al., 2009; Kenkel et al., 2013a) and holobiont thermal history (Brown et al., 2000, 2002a, 2002b). Therefore, it is the adaptive potential of the coral holobiont that will truly determine the ability of coral populations to respond to climate change (Iglesias-Prieto and Trench, 1997; LaJeunesse et al., 2010). Csaszar et al. (2010) report significant broad-sense heritabilities for coral growth based on variation among groups of clonal fragments sampled from two natural populations; however, these values must include a sizeable component attributable to prior environmental history of the sampled corals rather than genetic factors.

In the Florida Keys, Porites astreoides corals from inshore reefs exhibit elevated temperature tolerance in comparison with corals from offshore reefs (Kenkel et al., 2013a). These populations harbor

${ }^{1}$ Department of Integrative Biology, The University of Texas at Austin, 1 University Station C0990, Austin, TX, USA and ${ }^{2}$ Australian Institute of Marine Science, PMB3, Townsville MC, Townsville, Queensland, Australia

Correspondence: Dr CD Kenkel, Coral Health and Climate Change, Australian Institute of Marine Science, PMB 3, Townsville MC, Townsville, Queensland 4810, Australia. E-mail: carly.kenkel@gmail.com

Received 8 July 2014; revised 7 April 2015; accepted 21 April 2015; published online 17 June 2015 
indistinguishable Symbiodinium phylotypes but hosts are significantly genetically differentiated (Kenkel et al., 2013a) and exhibit divergent gene expression patterns (Kenkel et al., 2013b) suggesting that the coral host has a more prominent role in thermal adaptation in this species. However, it is not clear if observed thermotolerance differences in these populations are the result of heritable genetic variation or long-term acclimatization to their native habitat. In order to isolate the contribution of genetics, it is necessary to minimize the possibility that the differences in physiology and fitness-related traits are due to prior acclimatization of the organisms to different environments. Here, we used naive $P$. astreoides juveniles obtained from parental colonies from inshore and offshore populations, in order to minimize the effect of prior exposure to different environments. In addition, juvenile recruits were reared for 5 weeks in a common garden environment before conducting the thermal stress experiment to reduce the impact of maternal effects, as these effects are known to dissipate over the first month of life in marine invertebrate larvae (Cruz and Ibarra, 1997; Sman et al., 2009).

\section{MATERIALS AND METHODS}

\section{Coral collection, spawning and common rearing}

$P$. astreoides uses a brooding reproductive strategy. In brooding corals, eggs are fertilized internally and fully formed planulae are released in multiple reproductive cycles throughout the year (Richmond and Hunter, 1990; McGuire, 1998). Peak reproduction in $P$. astreoides occurs during the new moon, with the majority of larval release occurring in April/May (McGuire, 1998).

Twenty-five parent colonies of P. astreoides were collected on 19 April 2012 from a depth of 2-3 m from each of two sites: an inshore patch reef (Summerland Shoals Patch, $24^{\circ} 36.346 \mathrm{~N}, 81^{\circ} 25.742 \mathrm{~W}$ ) and an offshore reef (Dave's Ledge, $24^{\circ} 31.887 \mathrm{~N}, 81^{\circ} 29.013 \mathrm{~W}$ ) $9.9 \mathrm{~km}$ apart near Summerland Key under Florida Keys National Marine Sanctuary permit 2012-028. Colonies were immediately returned to Mote Marine Laboratory's Tropical Research Laboratory and placed in a shaded $(70 \%$ photosyntetically active radiation (PAR) reducing) flow-through seawater system (that is, raceway).

Each evening, from 19 April to 22 April, parent colonies were isolated in 15 -1 plastic tubs filled with $0.35 \mu \mathrm{m}$ filtered seawater placed into the raceway. As planulae larvae of brooding corals are competent to settle within hours of release (Isomura and Nishihira, 2001; Goodbody-Gringley, 2010), parent corals were placed on top of two $7.5 \mathrm{~cm}^{2}$ pre-conditioned terra cotta tiles to obtain families of juvenile recruits. Each morning, the remaining swimming larvae were collected by filtering the tub water gently through a $200 \mu \mathrm{M}$ Nitex mesh filter (Dynamic Aqua-Supply Ltd., Surrey, BC, Canada) and transferred to 1-1 plastic containers filled with $0.35 \mu \mathrm{m}$ filtered seawater by family. These remaining larvae were subsequently induced to settle onto the same preconditioned tiles with crustose coralline algae (Heyward and Negri, 1999).

In total, 38 corals, 19 inshore and 19 offshore, released sufficient larvae such that each coral family was represented by at least two tiles worth of juvenile recruits. On 25 April, parent corals were cut in half using a diamond blade tile saw. In addition, tiles were photographed to obtain baseline estimates for survival and growth measurements. Tiles and parent corals were then placed into racks in a single shaded (70\% PAR reducing, Supplementary Table S1) flow-through raceway with circulation pumps and left to acclimate for 5 weeks before the common garden heat stress experiment. Tiles were periodically cleaned and randomly repositioned in the raceway. Temperatures during the rearing period ranged from 26 to $28^{\circ} \mathrm{C}$, similar to temperature conditions experienced at the sites of collection (Supplementary Figure S1).

\section{Common garden experiment}

Common garden conditions were designed to reflect temperatures commonly experienced by reefs in the Florida Keys, which are known to elicit populationlevel variation in growth and bleaching (Kenkel et al., 2013a). On 28 May 2012, all parent colony halves were buoyant weighted in duplicate (Davies, 1989) and tiles were again photographed to obtain post-rearing measures of growth and survival. Parent colony halves and recruit tiles were then randomly assigned to a temperature treatment, a tank within that treatment and a specific position within that tank ( $n=4$ parent halves and 4-6 tiles per tank). Temperature treatment consisted of two shaded (70\% PAR reducing) raceways, large fiberglass troughs with seawater taps and drains, each holding eight 40-1 aquaria with clear plastic lids, with four control and four elevated temperature treatment tanks per raceway. Control temperature treatment was achieved by filling the 40-1 tanks with seawater, equipping each tank with a 2-W aquarium pump (Hesen, Ningbo Hesen Arts and Crafts Co. Ltd., Zhejiang, China) and allowing water to flow through the raceway as a water bath. Elevated temperature treatment tanks were set up in exactly the same manner, but each individual tank was also equipped with a $200-\mathrm{W}$ aquarium heater (Marineland, Blacksburg, VA, USA) set to maximum heat. Temperatures were $28 \pm 0.4^{\circ} \mathrm{C}(n=4)$ in the control tanks and $30.9 \pm 1.1^{\circ} \mathrm{C}(n=4)$ in the heated tanks, measured at midday. Treatment continued for 2.5 weeks ( 16 days) with tank cleaning and $30-50 \%$ water changes performed three times each week to maintain salinity levels at 35 p.p.t.

\section{Trait measurements}

Following treatment, all parent fragments were cleaned using a small brush to remove any filamentous algal growth and again buoyant weighted in duplicate. Technical replicates of weight measurements for each coral half were averaged. Initial weight measurements were subtracted from final weight measurements and divided by the initial weight measurement to determine the proportion of weight gained over the 2.5-week treatment for each parent coral (Kenkel et al., 2013a). Bleaching phenotypes were also recorded for each parent fragment by scoring coral color against the Coral Health Chart (Siebeck et al., 2006).

Tiles were again photographed and images were color and contrast enhanced and analyzed using ImageJ (Rasband, 1997-2014). To determine juvenile growth for the two time periods, the first 5 weeks of rearing ( 25 April to 28 May) and the 2.5-week common garden experiment (28 May to 13 June), individual recruits and tiles were outlined and pixel area was recorded. Recruit pixel area was normalized by tile pixel area. The fold-change in area for each individual recruit (co-settled clumps of recruits were not included in this analysis) by time-point was calculated by dividing final area by initial area. Survival was assessed by calculating the difference in absolute number of recruits per tile at each time-point. Co-settled clumps of recruits were considered a single individual in terms of survival.

\section{Genotyping}

DNA was extracted following (Kenkel et al, 2013a) from 10 individual larvae from each of 10 families ( 5 inshore and 5 offshore, representing a range of early recruit survival rates). Each individual was genotyped at eight microsatellite loci (Kenkel et al., 2013a) following the PCR reaction conditions described in Davies et al., 2012. GENEMARKER software 1.70 (Soft Genetics, LLC., State College, PA, USA) was used to analyze electropherograms and alleles were scored manually based on amplicon size. One inshore family was discarded due to poor amplification across all samples. In addition, select individuals were discarded based on the presence of spurious amplification peaks. 77 individuals ( $n=5-10$ per family; $n=9$ families) were used in the subsequent statistical analyses.

\section{Statistical analyses}

All analyses were carried out using R 2.13.2 (R Development Core Team, 2013). Differences in parent growth were evaluated with respect to treatment and population of origin using a nested series of linear mixed models implemented in the lme4 package (Bates, 2005). Differences in adult bleaching score were evaluated with respect to treatment and population of origin using a nested series of cumulative link mixed models as implemented in the ordinal package (Christensen, 2012), using a probit link function. Differences in juvenile growth rate, expressed as the $\log _{2}$ (fold-change), were evaluated with respect to treatment, population of origin and time-point using a nested series of linear mixed models implemented in the nlme package (Pinheiro et al, 2013). For all models, treatment, origin, time-point and their interaction were modeled as fixed factors, with levels control/heat, inshore/offshore and 5-week rearing/2.5week experiment, respectively. For adult models, colony identity and treatment tank were included as scalar random factors. For juvenile models, individual 
recruit, tile and parent identity were included as scalar random factors. For linear models, the applicability of model assumptions (normality, homoscedasticity) to the data were verified using diagnostic plots. For parent traits, likelihood ratio tests (LRT) were used to evaluate individual factor significance, while a Wald test was run to evaluate factor significance for juvenile growth rates. Relationships between sibling growth under control and heat treatment and parent-offspring growth were evaluated with Pearson's product-moment correlations using the function cor.test(), after removing outliers. Populationlevel differences in the initial number of recruits per tile and standardized recruit size $\left[\log _{10}\right.$ (recruit area/tile area) $]$ were evaluated with Welch's $t$-tests using the function $t$.test.

The heritability models were fitted using the package MCMCglmm (Hadfield, 2010). Growth was modeled using log-transformed fold-changes in area as a response variable. Time-points were analyzed independently. The model for the rearing time-point included origin as a fixed effect and scalar random effects of tile (blocking factor) and parent (to capture broad-sense heritability). The model for the experimental time-point included origin, treatment and their interaction as fixed effects and scalar random effects of tile (blocking factor) and parent (to capture broad-sense heritability). In addition, the model included a treatment-specific effect of parent, to account for differences in residual variance among treatments. Survival was analyzed in a multinomial model, by comparing counts of living and dead recruits by tile for the rearing time-point. For the survival model, origin was included as a fixed factor and a random effect of parent was included to capture heritability. All MCMC chains were run for 50000 iterations, discarding the first 10000 as a burn-in period, after which the chain was sampled every 20 iterations resulting in 2000 samples of each parameter value. Mean and quantiles of the broad-sense heritability were then calculated as mean and quantiles of the sampled values of the random parental effect. To evaluate how much heritability was attributable to the origin of the parents (offshore or inshore), heritability estimates of the full model were compared to the model omitting the fixed effect of origin; in this case, the variance attributable to origin is absorbed within the general parental effect (broad-sense heritability). All models were run at least three times to ensure convergence.

The adegenet package (Jombart, 2008) was used to estimate $F_{\text {IS }}$ values for each individual with respect to population (inshore or offshore) using the function inbreeding(). $F_{I S}$ values were averaged by family. The relationship between mean $F_{\text {IS }}$ and mean percent survival by family was evaluated with a Pearson's product-moment correlation using the function cor.test().

\section{RESULTS}

\section{Recruitment by population}

A trend of higher numbers of recruits per tile was observed for inshore families $(P=0.1$, Figure 1a). Also, at the beginning of the 5-week rearing period inshore-origin recruits were 1.3 times larger on average than offshore-origin recruits $(P<0.001$, Figure $1 \mathrm{~b})$.

a

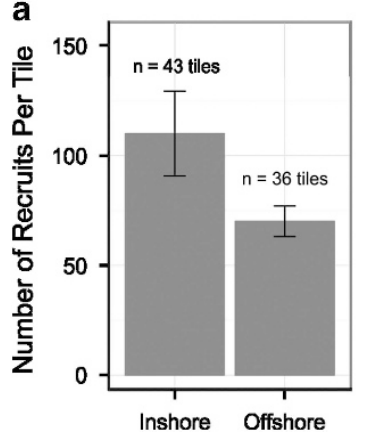

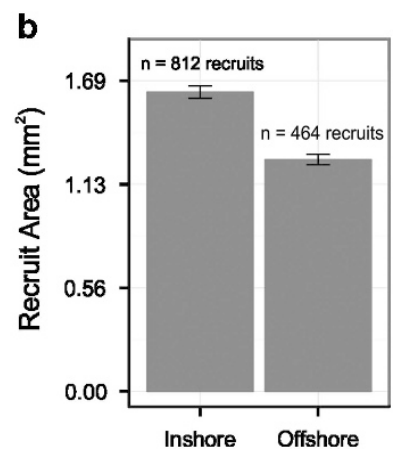

b

(b) of recruits produced by corals of different origin $( \pm$ s.e.m.) prior to beginning the 5-week rearing period.

\section{Parent coral response to temperature stress}

Growth of parent corals was uniformly reduced in response to the elevated temperature treatment, irrespective of coral origin $\left(P_{\mathrm{LRT}}<0.01\right.$, Figure 2a). Bleaching status of parent corals was significantly influenced by temperature treatment, with heat stress causing a greater loss of pigmentation relative to controls $\left(P_{\text {LRT }}<0.001\right.$, Figure 2b). Bleaching also revealed a marginally significant interaction-term effect, with offshore corals bleaching more than inshore corals in response to temperature stress $\left(P_{\mathrm{LRT}}=0.054\right.$, Figure 2b).

\section{Juvenile coral response to temperature stress}

No mortality was observed as a result of the 2.5-week heat stress experiment. Juvenile growth, however, was significantly different between inshore and offshore populations in response to heat stress when compared with growth trajectories in the first 5-week rearing period $\left(P_{\mathrm{WALD}}=0.0001\right.$, Figures $3 \mathrm{a}$ and $\mathrm{b}$; Table 1$)$. Overall, juveniles grew 1.5-fold more during the rearing period than during the experimental period $\left(P_{\mathrm{WALD}}<0.0001\right.$, Figure $\left.3 \mathrm{~b}\right)$. Offshore-origin recruits exhibited higher growth during the rearing period, by 1.1-fold on average (Figure 3b, 5 weeks), while inshore-origin recruits exhibited higher growth during the experimental period (1.1-fold, $P_{\text {WALD }}<0.0001$, Figure $3 \mathrm{~b}, 2.5$ weeks). Although temperature treatment was only applied during the last 2.5-week experimental period, recruit growth during the rearing period differed among tiles that were randomly assigned to control and heat treatments, possibly due to uncontrolled variation in rearing conditions. Inshore-origin recruits subsequently assigned to heat treatment exhibited the lowest growth rate during the rearing period; however, these individuals reversed their growth trajectories and substantially outgrew offshore-origin recruits during the heat stress experiment, by 1.1 -fold on average $\left(P_{\mathrm{WALD}}=0.0001\right.$, Figure $\left.3 \mathrm{~b}\right)$.
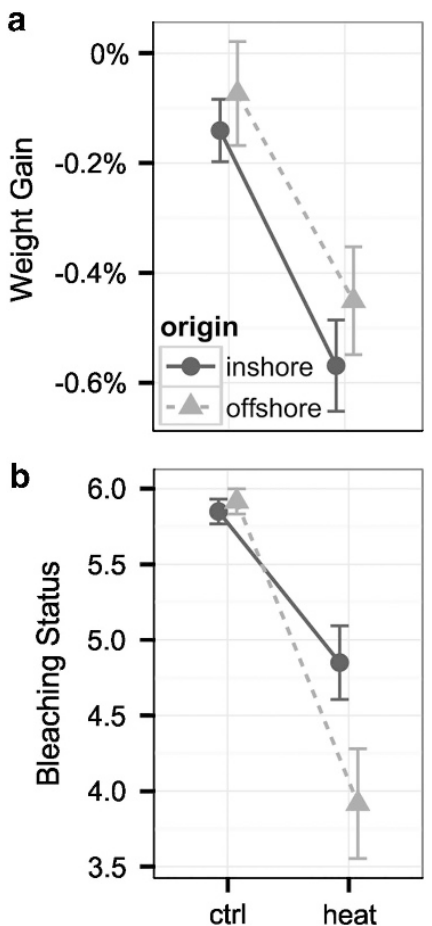

Figure 2 Fitness-related traits in parent corals. (a) Weight gain of parent corals (mean \pm s.e.m.) by origin and treatment following the 2.5-week thermal stress experiment. (b) Bleaching status of parent corals (mean \pm s.e.m.). 

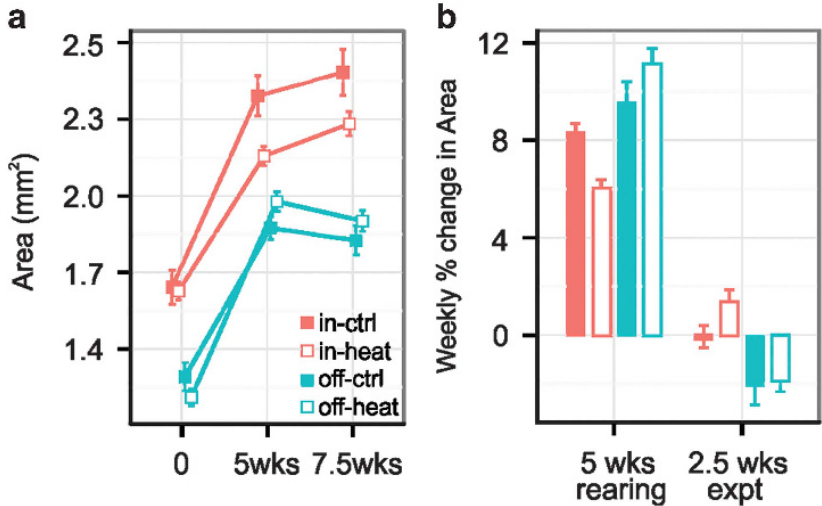

Figure 3 Growth of juvenile corals. (a) Absolute size of juvenile corals (recruit area \pm s.e.m.) by origin and treatment groups (note that treatment was applied only during the second time period, from 5 to 7.5 weeks). (b) Growth rate of recruits during the initial 5-week rearing period and the 2.5-week thermal stress experiment, expressed as the weekly percent change in area \pm s.e.m. for each time period.

Table 1 Wald test statistics for juvenile coral growth rate, $\log _{2}$ (Foldchange in normalized area), with respect to population origin (inshore/ offshore), treatment condition (control/heat) and time-point (5 weeks rearing/2.5 weeks stress experiment)

\begin{tabular}{lccrc}
\hline Factor & numDF & denDF & F-value & P-value \\
\hline Intercept & 1 & 1272 & 97.3 & $<0.0001$ \\
Origin & 1 & 36 & 2.7 & 0.11 \\
Treatment & 1 & 39 & 0.5 & 0.5 \\
Time & 1 & 1272 & 1034.2 & $<0.0001$ \\
Origin $\times$ treatment & 1 & 39 & 1.5 & 0.23 \\
Origin $\times$ time & 1 & 1272 & 70.1 & $<0.0001$ \\
Treatment $\times$ time & 1 & 1272 & 7.1 & 0.008 \\
Origin $\times$ treatment $\times$ time & 1 & 1272 & 15.5 & $<0.0001$ \\
\hline
\end{tabular}

\section{Heritability estimates for fitness-related traits}

The most pronounced heritabilities were detected during the initial rearing period. Origin had no effect, but family explained almost all of the variance in survival, with a calculated $H^{2}$ of 0.94 (95\% credible interval: $(0.86,0.99)$, Figure 4). Survival varied from 2 to $100 \%$, with a mean survival rate of $61 \%$ across families (Supplementary Figure S2). Though substantial, the variance in survival among larval families during the rearing period was independent of recruit density, and does not predict subsequent differences in growth during the common garden experiment (Supplementary Figure S3). Significant heritability was also detected for initial juvenile growth rates. The $H^{2}$ of initial growth rate was 0.27 (95\% confidence interval (CI) $(0.10,0.43$ ), Figure 4 ), of which $3 \%$ could be attributed to the effect of origin based in the decrease in heritability after accounting for the parental origin (origin-corrected $H^{2}=0.30,95 \%$ CI $(0.14,0.46)$ ). Furthermore, this variation in growth rate is independent of recruit density on tiles (Supplementary Figure S3).

Heritability estimates diminished following the 2.5-week common garden experiment. The family effect on growth was cut in half, with an $H^{2}$ of $0.15(95 \%$ CI $(0.03,0.25)$, Figure 4$)$. No variance was attributable to parental origin. In addition, heat treatment reduced the overall heritability of growth, though this difference was not significant (Figure 4). Control treatment yielded a growth $H^{2}$ of 0.15 (95\% CI $(0.002,0.30))$, while heat treatment yielded a growth $H^{2}$ of 0.10

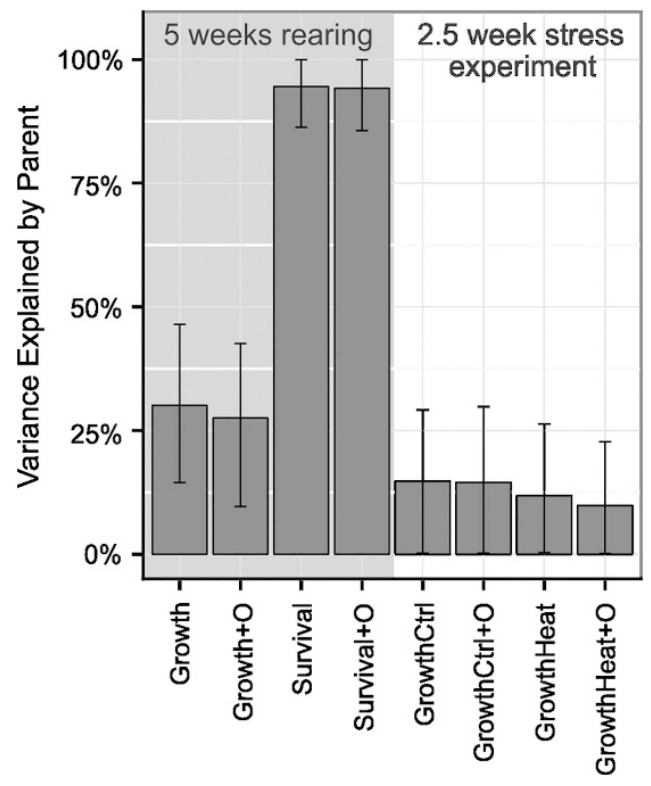

Figure 4 Broad-sense heritability estimates for survival and growth, expressed as the mean variance $( \pm 95 \% \mathrm{Cl})$ explained by parental effects, accounting for the effects of parental origin $(+0)$ and temperature treatment (Ctrl, heat) for each time-point, when meaningful.

(95\% CI $(0.002,0.23))$. Accounting for the effects of temperature treatment reduced heritability estimates overall, but estimates did not differ between treatments (Figure 4).

As a secondary validation of trait heritability, we evaluated trait correlations between parents and offspring as well as for recruit families under different treatments. Significant positive relationships were observed for recruit growth under different treatments $(B=0.49$, $P=0.005$, Figure $5 \mathrm{a}$ ) and between weight gain of parent colonies and mean offspring growth rate, expressed in units of s.d. to account for differences in the recorded growth metric $(B=0.28, P=0.04$, Figure $5 \mathrm{~b}$ ), further supporting the observation of heritable variation in growth (Figure 3 ).

\section{Inbreeding and recruit mortality}

Nine families (four inshore and five offshore), representing a range of recruit survival values, from 40 to $100 \%$ were genotyped at eight microsattelite loci. We found no relationship between mean $F_{\mathrm{IS}}$ and mean percent survival by family (Figure 6).

\section{DISCUSSION}

\section{Heritability of fitness-related traits in corals}

Broad-sense heritability, $H^{2}$, describes the summed contribution of genetic, epigenetic and maternal effects in generating phenotypic variation (Falconer and Mackay, 1996). Although this metric is a good approximation of adaptive potential in long-lived, clonal organisms, such as corals (Csaszar et al, 2010), it is a fraction of phenotypic variance attributable to additive genetic effects (termed narrow-sense heritability, $h^{2}$ ) that determines the immediate response to selection (Falconer and Mackay, 1996). Since $h^{2}$ is part of $H^{2}$, our estimates of broad-sense heritability for growth and survival in two populations of $P$. astreoides (Figure 4) overemphasize the true adaptive potential in these traits. However, heritability estimates for fitnessrelated traits tend to be lower on average than estimates for morphological traits (Visscher et al, 2008). The magnitude of broadsense heritabilities reported here $(27-30 \%$ of the variation in growth 


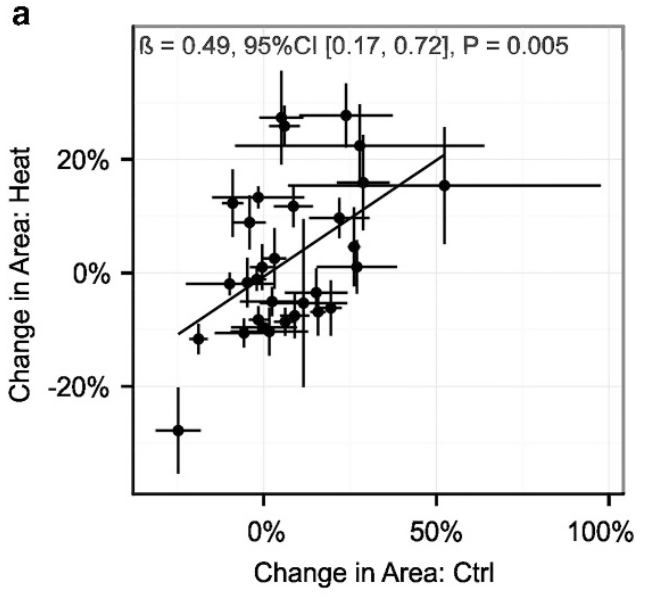

b

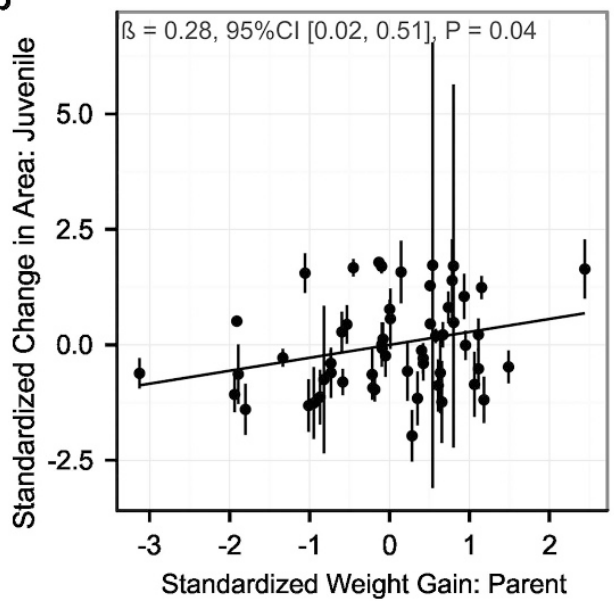

Figure 5 Heritability of recruit growth during the experimental period (weeks 5-7.5) illustrated by differences in mean ( \pm s.e.m.) growth (a) among recruit families under both control and heat treatment and by parent-offspring regressions for mean ( \pm s.e.m.) growth, expressed as s.d. from the mean (b).

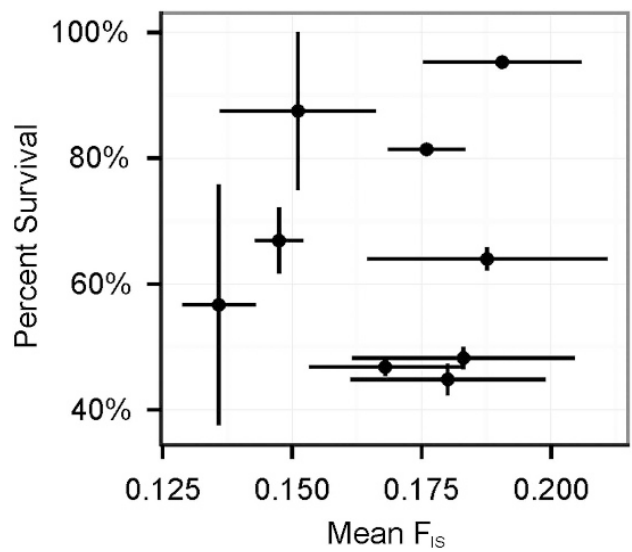

Figure 6 Mean $( \pm$ s.e.m.) percent survival as a function of mean ( \pm s.e.m.) $F_{\text {IS }}$ (a measure of inbreeding) by family.

and $94 \%$ of the variation in early survival, Figure 4) suggest that the additive genetic component is likely to be significant as well.

Alternatively, these large broad-sense heritabilities can be attributed to strong maternal effects. Brooded larvae of $P$. astreoides depend on the resources of the maternal coral for completion of their development, nutritional provisioning and even their Symbiodinium complement (Richmond and Hunter, 1990). Large maternal effects have been inferred for other brooding coral species. Size variation in the larvae, presumably reflective of developmental time and/or rate within the maternal colony, correlates with differential larval survival (Isomura and Nishihira, 2001). Furthermore, variation in the timing of larval release by the maternal colony can also affect the subsequent recruitment success (Nozawa and Harrison, 2005; Cumbo et al., 2012), although this effect is known to dissipate with time (GoodbodyGringley, 2010). Growth rates of brooded Favia fragum recruits exposed to different $\mathrm{pCO}_{2}$ treatments only begin to diverge after 6 weeks of treatment, possibly as maternal provisions are depleted (C Lowery, personal communication). The disparity between heritability estimates for growth rate during the rearing and experimental periods is most likely attributable to the dissipation of the maternal effects due to similar depletion of maternally derived resources (Figure 4), indicating that heritability estimates obtained during the 2.5-week experimental period are likely more reflective of the true additive component.

Though few estimates of trait heritability are available for any coral species, the $H^{2}$ of $0.10-0.15$ measured from among-families variation in later growth (Figure 4) is comparatively low, given that the additive component is some fraction of these values. Alternatively, narrowsense heritability can be measured as the slope of the regression line between mid-parental and offspring phenotypes (Falconer and Mackay, 1996). We regressed juvenile growth during the experimental period against maternal growth during that same period (Figure 5b). This slope corresponds to the combination of narrow-sense heritability and any persistent maternal effects that did not dissipate over the initial 5 weeks of rearing. The measured value $(0.28)$ is larger that the value estimated based on among-families variation, possibly reflecting higher power of the regression analysis. Meyer et al. (2009) used a diallel crossing design to evaluate the contribution of additive genetic variance to variation in a suite of traits under thermal stress in aposymbiotic larval families of Acropora millepora. They found that larval settlement rates and expression of a small heat shock protein ( $3 \gamma$-crystallin) both had significant additive genetic components of 0.49 and 0.38 , respectively (Meyer et al., 2009). A later study on the same species reports a similar estimate, with additive parental effects explaining $47 \%$ of the variance in larval settlement (Kenkel et al., 2011). Csaszar et al. (2010) estimated broad-sense heritabilities of symbiont, host and holobiont traits in adult A. millepora. Contrary to the results of Meyer et al. (2009), they report primarily nonsignificant heritabilities for host antioxidant gene expression (Csaszar et al., 2010). However, reported heritabilities for symbiont and holobiont traits are almost all significant and $H^{2}$ estimates for growth range from 0.19 to 0.59 (Csaszar et al., 2010). Still, it is not unusual to find heritability estimates that vary substantially among populations and species (Visscher et al., 2008), and considerable differences can be expected between species that differ in their reproductive strategy. A. millepora is a broadcast spawning coral, which releases egg-sperm bundles during annual reproductive events, and fertilization and larval development is independent of the maternal colony. Given the greater maternal investment of brooding species, strong maternal effects may be a more successful strategy for maximizing juvenile fitness. However, it must be noted that heritability is dependent on population-specific parameters (Falconer and Mackay, 1996). Additional heritability data for both brooding and broadcasting coral species is needed to fully evaluate this conjecture. 


\section{Population-level variation in temperature tolerance}

Adult corals recapitulate previously reported population-specific responses to common temperature stress (Kenkel et al, 2013a): growth was uniformly depressed and offshore $P$. astreoides corals bleached sooner and more severely than inshore corals (Figures $2 \mathrm{a}$ and $\mathrm{b}$ ). However, naïve juvenile offspring exhibited strikingly different growth phenotypes when challenged in the same temperature stress environment. Initially, offshore juveniles exhibited higher growth rates and individuals destined for heat treatment showed a significant growth advantage over inshore individuals assigned to the same treatment (Figure 3b). This pattern was completely reversed during the common garden stress experiment. Following this 2.5-week period, inshoreorigin juveniles displayed an overall growth advantage and significantly outgrew offshore-origin juveniles under heat treatment (Figure 3b).

The differences in juvenile growth profiles between populations may be due to different maternal investment in inshore and offshore corals and its subsequent dissipation during recruit development. Adult corals from offshore reefs tend to outgrow inshore-origin corals under control laboratory conditions (Kenkel et al., 2013a). In agreement with these earlier reports, a trend of elevated growth in offshore corals was also observed in the present study (Figure 2a), although it was not statistically significant $(P=0.16)$. Elevated growth rate in both adult corals from offshore and their offspring appears to contradict the expected life-history trade-off between fitness and reproduction, where presumably a high investment in parental growth should preclude strong investment in offspring provisioning (Stearns, 1992). This discrepancy could be resolved by accounting for the absolute numbers of offspring produced by inshore and offshore corals: the higher growth rate of offshore recruits could have come at a cost of fewer offspring per parent overall. Indeed, offshore corals produced fewer recruits (Figure 1a). Qualitative estimates of reproductive output by coral suggest this may result from reduced larval release by offshore corals rather than a reduction in settlement efficiency; however, additional work is needed to verify this conjecture. The higher growth rate of offshore recruits does not seem to be due solely to higher maternal provisioning either, as offshore-origin recruits were significantly smaller than inshore-origin recruits (Figure 1b). However, recruit size is not necessarily a good proxy of energetic content. For example, larval size is correlated with energetic content in bryozoans of the genus Bugula (Wendt, 2000), but not in intertidal mussels (Phillips, 2007). The relationship between larvae and recruit size and energetic stores is yet to be established for any coral. Furthermore, $P$. astreoides are capable of multiple spawning events annually (McGuire, 1998), raising a possibility of achieving higher seasonal reproductive output despite lower rate of offspring production at a given spawning event. Therefore additional data are needed to determine if inshore and offshore populations truly engage in alternative reproductive strategies.

Alternatively, the variation in growth among-families of naive juveniles before and after exposure to thermal stress may reflect genetically based thermotolerance responses. Adult inshore $P$. astreoides are more tolerant of thermal stress than offshore $P$. astreoides, as evidenced by differences in bleaching phenotype (Figure 2b,Kenkel et al., 2013a). If this difference is genetically based, naive inshore juveniles should display higher fitness under temperature stress than offshore juveniles. It must be noted that larvae were exposed to the parental environment when corals were at their native inshore and offshore reefs during the brooding period. P. astreoides release male gametes around the full moon and brooded larvae are released around the new moon (Chornesky and Peters, 1987; McGuire, 1998), indicating that larvae developed in different environments for at least two weeks in situ. However, it is unlikely that developing larvae experienced different temperature environments during this period. Though inshore reefs in the Florida Keys experience warmer summer temperatures and colder winter temperatures, fall and spring water temperatures are similar between inshore and offshore reefs (Kenkel et al., 2013a) and were not significantly different in April 2012 when adult corals were collected (Briceno and Boyer, 2012). Therefore, the observed growth advantage of the naive inshore juveniles under heat stress (Figure $3 \mathrm{~b}$ ) suggests that thermotolerance in this species is indeed genetically determined.

One possible mechanism underlying such heritable variation is differential expression of metabolic genes. Inshore and offshore adult $P$. astreoides display gene expression patterns that may reflect alternative energy allocation strategies (Kenkel et al., 2013b). Similar variation in recruit populations could underpin the differences in growth rates through time and in response to temperature stress, but additional transcriptomic studies are needed to validate this hypothesis.

Yet one more possible explanation for the variation in growth between populations is a difference in the hosted symbiont genotypes. As vertically transmitting brooding corals, $P$. astreoides are assumed to inherit their maternal symbionts (Thornhill et al., 2006) and early-life growth trends may reflect this heritable symbiont component. Although previous studies demonstrated that symbiont complements in inshore and offshore populations of $P$. astreoides are indistinguishable at the level of internal transcribed spacer 2 of the rRNA gene (Kenkel et al., 2013a), the possibility of functionally relevant variation elsewhere in the symbiont's genome cannot be excluded. Such genetic variation would be relevant for understanding evolutionary adaptation in this coral species as long as the evolutionary histories of host and symbiont remain linked through vertical transmission. The extent to which this relationship can be maintained in natural coral populations in the long term remains unknown and merits an indepth investigation in the future using high-resolution genetic markers.

\section{Variation in early-life mortality: inbreeding and genetic load}

The incredibly high heritability $\left(H^{2}=0.94\right)$ of early juvenile mortality (Figure 4) implies that nearly all of the variation in mortality, which ranged from $97 \%$ to $0 \%$ among-families, is attributable to some form of parental effects. Many marine larvae experience uniformly high mortality rates early in life, exhibiting the Type 3 survivorship curve typically taught in population ecology courses (Rauschert, 2010). In Pacific oysters, this pattern has been attributed to genetic load and reflects the effect of deleterious alleles segregating within the natural population (Launey and Hedgecock, 2001). In the coral A. palmata, reproductive incompatibilities between unique parent corals have been shown to affect fertilization success and some larval phenotypes, such as swimming speed (Baums et al, 2013). In the case of P. astreoides, indiscriminate early-life mortality in some, but not all, families could be explained by the unmasking of recessive deleterious alleles as a result of inbreeding. Inbreeding has been observed in other brooding coral species (Ayre and Hughes, 2000; Ayre and Miller, 2006) and likely results from short-range larval dispersal typical of many brooding species (Hellberg, 1996; Nishikawa et al., 2003; Underwood et al., 2007) generating highly related local populations. We estimated inbreeding for a subset of individual larvae from nine families spanning a range of different survival values. We find no relationship between mean $F_{\text {IS }}$ and percent survival across families (Figure 6), suggesting that some other mechanism may be driving variation in juvenile mortality in these families. 


\section{Heritability and selection: implications for 'human-assisted} evolution'

The worldwide decline of coral populations in this era of rapid climate change (Gardner et al., 2003; Hoegh-Guldberg et al., 2007) has prompted an interest in 'human-assisted evolution' as potential means to breed more tolerant coral populations capable of coping with future climate warming and ocean acidification (van Oppen et al., 2015). Understanding heritabilities and the underlying genetic architecture of targeted traits will be critical for evaluating the potential of such selective breeding programs. The breeder's equation was developed to improve animal and plant yields under artificial selection by providing a prediction of the phenotypic response to selection on a quantitative trait (Falconer and Mackay, 1996). The product of the narrow-sense heritability of a trait $\left(h^{2}\right)$ and the strength of selection (s) predict the mean change in trait value per generation $(\Delta Z$, expressed in units of standard deviations of the initial group), although more accurate predictions are obtained when genetic covariances of additional traits correlated with the trait of interest are taken into account (Lande, 1979). Given the heritabilities estimated here and assuming strong selection (only individuals in the top $10 \%$ of trait values are allowed to reproduce), growth rate will increase by at most $0.04 \sigma$ per generation. Although there are many caveats associated with estimating the effects of artificial selection (Hill and Caballero, 1992), this rough calculation suggests that, at least for this species, several generations of selective breeding will be necessary to evolve populations beyond the range of growth phenotypes presently observed. As oceans are predicted to warm by $1-3{ }^{\circ} \mathrm{C}$ within the next century (IPCC, 2013), such an implementation of 'human-assisted evolution' would not be very efficient. The prospects might be better if greater genetic variation is accessed by bringing in individuals from other parts of the species' range (that is, by combining human-assisted evolution with humanassisted migration, Aitken and Whitlock, 2013; van Oppen et al., 2015).

\section{CONCLUSIONS}

Our results represent the first estimates of broad-sense heritabilities in fitness-related traits for a Caribbean reef-building coral. In addition, naive juvenile corals representing inshore and offshore populations exhibited divergent growth patterns in response to heat stress. These results support the hypothesis that previously observed divergence in thermotolerance between adult coral populations is due, at least in part, to genetic effects. However, additional heritability estimates are needed for other Caribbean species to gain insight into the potential for genetic adaptation of these endangered organisms in the face of climate change. Future work will be aimed to understand the molecular basis of population-level variation in temperature tolerance and evaluate the role of natural selection in producing it.

\section{DATA ARCHIVING}

All raw data files, images and $\mathrm{R}$ scripts available from the Dryad Digital Repository: http://dx.doi.org/10.5061/dryad.q7k8j.

\section{CONFLICT OF INTEREST}

The authors declare no conflict of interest.

\section{ACKNOWLEDGEMENTS}

We thank M Stiber, W Zaragoza, K Ritchie and C Page for their help with $P$. astreoides spawning and long-term rearing of juvenile recruits. Funding for this study was provided by UT Austin's EEB DDIG-like grant, a PEO Scholar Award and PADI Foundation grant no. 5244 to CDK and the National Science Foundation grant DEB-1054766 to MVM.
Abrego D, Ulstrup KE, Willis BL, van Oppen MJH (2008). Species-specific interactions between algal endosymbionts and coral hosts define their bleaching response to heat and light stress. Proc R Soc B Biol Sci 275: 2273-2282.

Aitken SN, Whitlock MC (2013). Assisted gene flow to facilitate local adaptation to climate change. Annu Rev Ecol Evol Syst 44: 13-22.

Ayre DJ, Hughes TP (2000). Genotypic diversity and gene flow in brooding and spawning corals along the Great Barrier Reef, Australia. Evolution 54: 1590-1605.

Ayre DJ, Miller K (2006). Random mating in the brooding coral Acropora palifera. Mar Ecol Prog Ser 307: 155-160.

Baird AH, Bhagooli R, Ralph PJ, Takahashi S (2009). Coral bleaching: the role of the host. Trends Ecol Evol 24: 16-20.

Bates D (2005). Fitting linear mixed models in R. R News 5: 4

Baums I, Devlin-Durante M, Polato N, Xu D, Giri S, Altman N et al. (2013). Genotypic variation influences reproductive success and thermal stress tolerance in the reef building coral, Acropora palmata. Coral Reefs 32: 703-717.

Briceno HO, Boyer JN. (2012). Southeast Environmental Research Center. Florida International University: Miami.

Brown BE (1997). Coral bleaching: causes and consequences. Coral Reefs 16: S129-S138.

Brown BE, Downs CA, Dunne RP, Gibb SW (2002a). Exploring the basis of thermotolerance in the reef coral Goniastrea aspera. Mar Ecol Prog Ser 242: 119-129.

Brown BE, Dunne RP, Goodson MS, Douglas AE (2000). Marine ecology-bleaching patterns in reef corals. Nature 404: 142-143.

Brown BE, Dunne RP, Goodson MS, Douglas AE (2002b). Experience shapes the susceptibility of a reef coral to bleaching. Coral Reefs 21: 119-126.

Burrows MT, Schoeman DS, Buckley LB, Moore P, Poloczanska ES, Brander KM et al. (2011). The pace of shifting climate in marine and terrestrial ecosystems. Science 334: 652-655.

Charmantier A, Garant D (2005). Environmental quality and evolutionary potential: lessons from wild populations. Proc $R$ Soc B Biol Sci 272: 1415-1425.

Chornesky EA, Peters EC (1987). Sexual reproduction and colony growth in the scleractinian coral Porites astreoides. Biol Bull 172: 161-177.

Christensen RHB (2012). Ordinal—Regression Models for Ordinal Data. Available at http:// www.cran.r-project.org/package $=$ ordinal/.

Cruz P, Ibarra AM (1997). Larval growth and survival of two catarina scallop (Argopecten circularis, Sowerby, 1835) populations and their reciprocal crosses. $J$ Exp Mar Biol Ecol 212: 95-110.

Csaszar NBM, Ralph PJ, Frankham R, Berkelmans R, van Oppen MJH (2010). Estimating the potential for adaptation of corals to climate warming. Plos One 5: 3.

Cumbo V, Fan T-Y, Edmunds PJ (2012). Physiological development of brooded larvae from two pocilloporid corals in Taiwan. Mar Biol 159: 2853-2866.

Davies PS (1989). Short-term growth measurements of corals using an accurate buoyant weighing technique. Mar Biol 101: 389-395.

Davies SW, Rahman M, Meyer E, Green EA, Buschiazzo E, Medina M et al. (2012). Novel polymorphic microsatellite markers for population genetics of the endangered Caribbean star coral, Montastraea faveolata. Mar Biodivers; 43: 167-172.

Falconer D, Mackay T (1996). Introduction to Quantitative Genetics. Longman: New York.

Gardner TA, Cote IM, Gill JA, Grant A, Watkinson AR (2003). Long-term region-wide declines in Caribbean corals. Science 301: 958-960.

Goodbody-Gringley G (2010). Diel planulation by the brooding coral Favia fragum (Esper). J Exp Mar Biol Ecol 389: 70-74.

Hadfield JD (2010). MCMC Methods for multi-response generalized linear mixed models: the MCMCgImm R package. J Stat Softw 33: 1-22.

Hellberg ME (1996). Dependence of gene flow on geographic distance in two solitary corals with different larval dispersal capabilities. Evolution 50: 1167-1175.

Heyward A, Negri A (1999). Natural inducers for coral larval metamorphosis. Coral Reefs 18: 273-279.

Hill WG, Caballero A (1992). Artificial selection experiments. Annu Rev Ecol Syst 23: 287-310.

Hoegh-Guldberg O, Mumby PJ, Hooten AJ, Steneck RS, Greenfield P, Gomez E et al. (2007). Coral reefs under rapid climate change and ocean acidification. Science $\mathbf{3 1 8}$ 1737-1742.

Howells EJ, Beltran VH, Larsen NW, Bay LK, Willis BL, van Oppen MJH (2011). Coral thermal tolerance shaped by local adaptation of photosymbionts. Nat Clim Change 2: $116-120$.

Hughes TP, Baird AH, Bellwood DR, Card M, Connolly SR, Folke C et al. (2003). Climate change, human impacts, and the resilience of coral reefs. Science 301: 929-933.

Iglesias-Prieto R, Trench RK (1997). Photoadaptation, photoacclimation and niche diversification in invertebrate-dinoflagellate symbioses. Proceedings of the 8th International Coral Reef Symposium 2: 1319-1324.

IPCC (2013). Climate Change 2013. In: Stocker TF, Qin D, Plattner G-K, Tignor M, Allen SK, Boschung J et al. (eds). Cambridge University Press: Cambridge and New York.

Isomura N, Nishihira M (2001). Size variation of planulae and its effect on the lifetime of planulae in three pocilloporid corals. Coral Reefs 20: 309-315.

Jokiel P (2004). Temperature stress and coral bleaching. In: Rosenberg E, Loya Y (eds) Coral Health and Disease. Springer-Verlag: Heidelberg. pp 401-425. 
Jombart T (2008). adegenet: an R package for the multivariate analysis of genetic markers Bioinformatics 24: 1403-1405.

Jones A, Berkelmans R (2010). Potential costs of acclimatization to a warmer climate: growth of a reef coral with heat tolerant vs sensitive symbiont types. Plos One 5 e10437.

Kenkel C, Goodbody-Gringley G, Caillaud D, Davies SW, Bartels E, Matz M (2013a). Evidence for a host role in thermotolerance divergence between populations of the Mustard hill coral (Porites astreoides) from different reef environments. Mol Ecol 22 4335-4348.

Kenkel C, Meyer E, Matz M (2013b). Gene expression under chronic heat stress in populations of the Mustard hill coral (Porites astreoides) from different thermal environments. Mol Ecol 22: 4322-4334.

Kenkel C, Traylor M, Wiedenmann J, Salih A, Matz M (2011). Fluorescence of coral larvae predicts their settlement response to crustose corraline algae and reflects stress. Proc $R$ Soc B Biol Sci 278: 2691-2697.

LaJeunesse TC, Smith R, Walther M, Pinzon JH, Pettay DT, McGinley M et al. (2010) Host-symbiont recombination versus natural selection in the response of coraldinoflagellate symbioses to environmental disturbance. Proc $R$ Soc B Biol Sci 277: 2925-2934.

Lande R (1979). Quantitative genetic analysis of multivariate evolution, applied to brain: body size allometry. Evolution 33: 402-416.

Launey S, Hedgecock D (2001). High genetic load in the Pacific oyster Crassostrea gigas. Genetics 159: 255-265.

Little AF, van Oppen MJH, Willis BL (2004). Flexibility in algal endosymbioses shapes growth in reef corals. Science 304: 1492-1494.

McGuire MP (1998). Timing of larval release by Porites astreoides in the northern Florida Keys. Coral Reefs 17: 369-375.

Meyer E, Davies S, Wang S, Willis BL, Abrego D, Juenger TE et al. (2009). Genetic variation in responses to a settlement cue and elevated temperature in the reef-building coral Acropora millepora. Mar Ecol Prog Ser 392.

Muscatine $L$ (1990). The role of symbiotic algae in carbon and energy flux in reef corals. In: Dubinsky (ed) Ecosystems of the world 25: Coral reefs. Elsiever: New York. pp 75-87.

Nishikawa A, Katoh M, Sakai K (2003). Larval settlement rates and gene flow of broadcastspawning (Acropora tenuis) and planula-brooding (Stylophora pistillata) corals. Mar Ecol Prog Ser 256: 87-97.

Nozawa Y, Harrison PL (2005). Temporal settlement patterns of larvae of the broadcast spawning reef coral Favites chinensis and the broadcast spawning and brooding reef coral Goniastrea aspera from Okinawa, Japan. Coral Reefs 24: 274-282.
Oliver TA, Palumbi SR (2011). Many corals host thermally resistant symbionts in hightemperature habitat. Coral Reefs 30: 241-250.

Phillips NE (2007). High variability in egg size and energetic content among intertidal mussels. Biol Bull 212: 12-19.

Pinheiro J, Bates D, DebRoy S, Sarkar D, Core Team. R (2013). nIme: Linear and Nonlinear Mixed Effects Models. Available at http://CRAN.R-project.org/package $=$ nlme.

Rasband WS. (1997-2014). ImageJ. U.S. National Institutes of Health. Bethesda: Maryland.

Rauschert E (2010). Survivorship curves. Nature Education Knowledge 3: 18 .

Richmond RH, Hunter CL (1990). Reproduction and recruitment of corals-comparisons among the caribbean, the tropical pacific, and the Red Sea. Mar Ecol Prog Ser 60 185-203.

Robinson JD, Warner ME (2006). Differential impacts of photoacclimation and thermal stress on hte photobiology of four different phylotypes of Symbiodinium (Pyrrhophyta). J Phycol 42: 568-579.

Siebeck UE, Marshall NJ, Klueter A, Hoegh-Guldberg 0 (2006). Monitoring coral bleaching using a colour reference card. Coral Reefs 25: 453-460.

Sman J, Phillips NE, Pfister CA (2009). Relative effects of maternal and juvenile food availability for a marine snail. Ecology 90: 3119-3125.

Stearns SC (1992). The Evolution of Life Histories. Oxford University Press: Oxford, UK.

R Development Core Team (2013). R: A Language and Environment for Statistical Computing. R Foundation for Statistical Computing: Vienna, Austria. Available at http://www.R-project.org/.

Thornhill DJ, Fitt WK, Schmidt GW (2006). Highly stable symbioses among Western Atlantic brooding corals. Coral Reefs 25: 515-519.

Ulstrup KE, Berkelmans R, Ralph PJ, van Oppen MJH (2006). Variation in bleaching sensitivity of two coral species across a latitudinal gradient on the Great Barrier Reef the role of zooxanthellae. Mar Ecol Prog Ser 314: 135-148.

Underwood JN, Smith LD, Van Oppen MJH, Gilmour JP (2007). Multiple scales of genetic connectivity in a brooding coral on isolated reefs following catastrophic bleaching. Mol Ecol 16: 771-784.

van Oppen MJH, Oliver JK, Putnam HM, Gates RD (2015). Building coral reef resilience through assisted evolution. Proc Natl Acad Sci USA 112: 2307-2313.

Visscher PM, Hill WG, Wray NR (2008). Heritability in the genomics era-concepts and misconceptions. Nat Rev Genet 9: 255-266.

Wendt DE (2000). Energetics of larval swimming and metamorphosis in for species of Bugula (bryozoa). Biol Bull 198: 346-356.

Supplementary Information accompanies this paper on Heredity website (http://www.nature.com/hdy) 